Acta Poetica $26(1-2)$

PRIMAVERA-OTOÑO

2005

\title{
Cómo hemos llegado a conocer el romancero sefardí
}

\author{
Paloma Díaz-Mas
}

En este artículo se ofrece una síntesis de cómo el romancero sefardí ha llegado a ser conocido y tenido en cuenta por parte del los estudiosos del hispanismo: las primeras noticias aportadas por filólogos romanistas que ya a finales del siglo XIX recogieron muestras de la literatura oral en sus encuestas de campo, la intervención de los propios publicistas sefardíes, el estudio filológico del romancero desde principios del siglo xx, la atención a las ediciones aljamiadas o a los romances citados en colecciones de himnos hebreos y, por último, la recopilación de romances en manuscritos de uso personal por parte de los propios sefardíes y, sobre todo, de las mujeres sefarditas.

This paper offers a synthesis of the process by which the romancero sefardi has been known and taken into account by researchers of the Hispanic world: the first news given by Romanist philologists who, at the end of the XIX Century, recollected in their field surveys some of this oral tradition; the role of the Sephardic publicists; the philological study of the romancero at the beginning of the $\mathrm{xx}$ Century; the attention drawn by the aljamiada editions or by the romances quoted in the Hebrew Hymn collections; and, finally, the compilation of romances taken from personal writings of the Sephardic community and, overall, from the Sephardic women. 
Acta Poetica 26 (1-2)

PRIMAVERA-OTOÑO

2005

Paloma Díaz-Mas

Instituto de la Lengua Española del CSIC

\section{Cómo hemos llegado a conocer el romancero sefardí}

Una de las ramas más ricas y fecundas del romancero es la sefardí; es decir, la que durante siglos mantuvieron viva los judíos descendientes de los expulsados de la Península Ibérica a finales de la Edad Media. ${ }^{1}$

Asentados en un entorno no hispanohablante (como el Oriente mediterráneo o el norte de África), los sefardíes conservaron el uso del español como lengua de comunicación y literaria hasta las primeras décadas del siglo xx. Su literatura estuvo compuesta por una variedad de géneros, que van desde las traducciones de la Biblia hasta la poesía estrófica, los comentarios bíblicos, los tratados de moral, la novela, el teatro o el periodismo. ${ }^{2} \mathrm{Y}$ también, cómo no, por la literatura de transmisión mayoritariamente oral (cuentos, canciones, romances); géneros que ya existían en la España medieval y que entre los sefardíes pervivieron, conservando temas antiguos e incorporando a lo largo de los siglos temas y motivos nuevos, de creación propia o tomados de la literatura de los pueblos con los que los judíos de origen hispánico convivían (es significa-

\footnotetext{
${ }^{1}$ Una panorámica sobre los sefardíes y su cultura puede encontrarse en DíazMas 1986 (y su versión en inglés de 1992).

2 Para la literatura sefardí de transmisión escrita es fundamental la monografía de Romero 1992.
} 
tivo, por ejemplo, que varios romances de los sefardíes de Macedonia sean, en realidad, traducciones o adaptaciones en judeoespañol de baladas griegas o de temas balcánicos). ${ }^{3}$

Reflexionar acerca de cómo hemos llegado a conocer el romancero sefardí de las distintas épocas equivale a reflexionar por qué vías y en qué ámbitos se transmitieron los romances, quiénes eran los usuarios de este tipo de poesía tradicional y qué función tenían los romances en sus vidas; en último término, a través de la historia y de los modos de transmisión de este género podemos entrever la historia interna y la evolución social y cultural de las propias comunidades sefardíes y la relación del mundo occidental (y, muy especialmente, de España) con los sefarditas.

\section{La vida oral del romancero y las encuestas de campo de los estudiosos de la Filología Románica}

El primer conocimiento que tuvo el mundo occidental del romancero sefardí fue a través de dos vías: a) los materiales recogidos en encuesta de campo por filólogos; y b) las muestras publicadas por algunos hombres de letras sefardíes, conocedores de primera mano de esa tradición oral.

Las primeras encuestas de campo de la tradición sefardí fueron llevadas a cabo por filólogos romanistas y estaban presididas, como no podía ser menos, por un interés más lingüístico que literario. Lo que atraía a los estudiosos era el estudio de una variedad lingüística románica (el judeoespañol) que se había mantenido viva y había evolucionado en entornos de lenguas no románicas (turco, árabe, griego, serbocroata, rumano, etc.), desarrollando una serie de rasgos específicos que la diferenciaban tanto del español peninsular, insular y americano como de otras lenguas románicas. En el curso de las inves-

\footnotetext{
3 Véase Armistead y Silverman 1982, 151-178.
} 
tigaciones lingüísticas se realizó una labor de recogida de materiales que a veces incluía textos de la literatura escrita (tal es el caso de Wagner 1930), pero que fundamentalmente se nutrió de transcripciones de manifestaciones orales: narraciones espontáneas y también muestras de la literatura de transmisión oral, como cuentos, romances y canciones. Así recogieron y publicaron romances sefardíes algunos de los más prestigiosos romanistas, como Leo Wiener (1903-1904), el ya mencionado Max Leopod Wagner (por ejemplo, en 1914 y 1930) o Cynthia Crews (así en 1935 y en su póstumo de 1979).

\section{Los periodistas sefardíes, entre tradición y modernidad}

Por los mismos años en que los pioneros de la romanística empezaban a interesarse por el judeoespañol, algunos periodistas sefardíes dieron también a conocer muestras del romancero en el ámbito académico. Así, Abraham Danon publicó en fecha tan temprana como 1896 una colección de romances de Turquía, y Abraham Galante dio a conocer otros catorce textos en 1903.

Uno y otro caso son significativos: Danon recibió formación rabínica, pero también fue director de una escuela de la Alliance Israélite Universelle en Estambul, traductor al hebreo de obras de la cultura occidental (desde Virgilio a Víctor Hugo), participó en París en el Congreso de Orientalistas de 1897 y fundó en Edirne el periódico El progreso, que se publicaba en turco, hebreo y judeoespañol aljamiado; Galante era un periodista formado a la occidental, director de varios periódicos aljamiados en judeoespañol, editor y dramaturgo en lengua sefardí y, simultáneamente, autor de una serie de trabajos históricos en francés sobre las comunidades sefardíes de Oriente. Es decir, representan un tipo de sefardí muy característico de la segunda mitad del siglo XIX y las primeras déca- 
das del xx: formados a la occidental, tienen el francés como lengua de cultura (significativamente, las obras históricas de Galante están en francés, y tanto su artículo sobre romances como el de Danon aparecieron en revistas francesas); y, al mismo tiempo, mantienen una faceta de divulgadores que les hace publicar en su lengua materna obras de creación literaria y periódicos dirigidos a las clases sefardíes más populares, a los artesanos, pequeños comerciantes, obreros o trabajadores de oficios ínfimos (como los descargadores de muelle o los vendedores ambulantes), que no tienen acceso a la educación en escuelas occidentales, no conocen otra lengua que el judeoespañol y sólo saben leer el alfabeto hebreo (la mayor parte de esas obras y periódicos se publicaban en judeoespañol aljamiado, es decir, escrito con letras hebreas). Pero, por otro lado - y pese a su formación occidental y afrancesada- gentes como Galante o Danon conocen de primera mano, por transmisión oral en el entorno doméstico de su infancia, la literatura tradicional de romances y canciones. Los primeros sefardíes que publicaron romances nos ofrecen, así, una radiografía de los cambios culturales que se operaron en el mundo sefardí desde la segunda mitad del siglo XIX, cuando el establecimiento de escuelas occidentales (y especialmente las francesas de la Alliance Israélite Universelle) en Oriente y en el Norte

de África abrió a la incipiente burguesía sefardí el acceso a la cultura occidental, con sus consiguientes posibilidades culturales, laborales y de relaciones y difusión.

\section{Los estudios filológicos del romancero sefardí}

La labor de encuesta iniciada por algunos de los padres de la Filología Románica fue continuada a lo largo del siglo xx por filólogos que empezaron a prestar atención, no ya sólo a los aspectos lingüísticos, sino también a los estrictamente literarios. 
En España, fue fundamental la labor de Ramón Menéndez Pidal, con su interés por el romancero como manifestación de la épica hispánica.

Menéndez Pidal hizo con sus colaboradores —entre los cuales se encontraba su propia mujer, María Goyri- numerosas encuestas de campo en el ámbito hispánico. ${ }^{4}$ Pero es más que probable que su interés por la tradición sefardí se viese influida por la campaña en pro de los judíos de origen hispánico promovida a partir de 1904 por el senador Ángel Pulido Fernández.

Pulido era médico de profesión, seguidor político de Emilio Castelar y, por tanto, representante de la corriente política llamada regeneracionismo, que propugnaba la regeneración de la vida política, social y económica de la para entonces atrasada España. En un viaje por los Balcanes conoció a Enrique Bejarano, un sefardí de Bucarest profesor de español; el contacto directo con este sefardí, el descubrimiento de que en Oriente había ciudadanos de origen hispánico que hablaban una variedad del español (pese a haber sido expulsados de España hacía más de cuatro siglos) conmovieron a Pulido, quien desde entonces emprendió una apasionada campaña propugnando el acercamiento de España a los sefardíes y la adopción de medidas políticas en favor de ese proyecto.

Que Menéndez Pidal tuvo conocimiento de la campaña de Pulido es evidente, no sólo porque dio pie a un cierto debate nacional (en el Senado y en la prensa) y porque el senador publicó dos libros sobre el tema que alcanzaron bastante difusión (1904 o 1905), sino porque el propio Pulido se encargó de informar y tratar de movilizar personalmente a buena parte de los intelectuales españoles de la época; y, concretamente, pidió el apoyo de Menéndez Pidal para que varios escritores e

\footnotetext{
${ }^{4}$ Los romances y canciones sefardíes de la colección de Ramón Menéndez Pidal y María Goyri están catalogados en Armistead 1978, donde se pueden encontrar también noticias sobre las encuestas de campo (vol. I, 7-23); véase también Catalán 2001, especialmente 30-37, 66-76 y 88-96.
} 
intelectuales sefardíes fuesen nombrados académicos correspondientes de la Real Academia Española.

En poco más de un año, Pulido desarrolló también una intensa labor de intercambio de correspondencia, carteándose con casi 150 sefardíes de las más diversas partes del mundo. En las cartas que recibió (y que en parte reproduce en su libro de 1905) encontramos el retrato de un sector del mundo sefardí de la época, precisamente el más acomodado y más integrado en el sistema: militares y médicos de sultanes, profesionales como médicos o ingenieros, comerciantes y banqueros, jóvenes educadas en las escuelas francesas e italianas; muchos de sus corresponsales eran políglotas y varios de ellos habían vivido en distintos países del mundo. Desde Turquía hasta Inglaterra, desde Marruecos hasta Rumania, desde México o Argentina hasta Italia, las cartas remitidas al senador español nos ofrecen también una panorámica de los lugares de asentamiento sefardíes en los inicios del siglo xx, cuando todavía existían las comunidades tradicionales (hoy casi todas prácticamente desaparecidas) de Turquía, Grecia, los Balcanes, Oriente Próximo o el norte de África, pero se había iniciado ya la llamada diáspora secundaria, es decir, la emigración masiva hacia países europeos y americanos, que alcanzaría su culmen entre 1912 y la década de los años 50.

Varios de los corresponsales incluyen en sus cartas datos sobre la vida tradicional de sus comunidades — una vida tradicional en la que ellos apenas no participaban, o que rememoraban como un recuerdo de infancia-, e incluso muestras de la literatura de tradición oral, entre ellas varios romances.

El propio Pulido remitió algunos de esos romances a Menéndez Pidal. Y además parte de los contactos del senador los utilizó Menéndez Pidal cuando envió — becado por la Junta de Ampliación de Estudios - a Manuel Manrique de Lara a hacer encuestas masivas y sistemáticas entre los sefardíes de Oriente (en 1911) y de Marruecos (en 1915-1916). Es posible que los 
corresponsales de Pulido sirvieran a Manrique como forma de presentarse e introducirse en las comunidades judías orientales o del norte de Marruecos, pero parece que los contactos directos fueron poco productivos como informantes propiamente dichos; y con razón: mientras los sefarditas con los que se carteaba Pulido eran gentes acomodadas, pertenecientes a la incipiente burguesía sefardí, que se habían educado y vivían a la occidental, seguramente Manrique encontró sus mejores informantes entre hombres y, sobre todo, mujeres de las clases más populares y menos ilustradas, entre quienes estaba más vigente la transmisión oral de saberes y la literatura oral (Díaz-Mas 2001).

Otro de los más productivos colaboradores de Menéndez Pidal en la exploración del romancero judeoespañol fue, precisamente, un sefardí de Tánger residente en Lisboa: José Benoliel. Nos encontramos aquí nuevamente con un caso parecido al de Danon o al de Galante: un sefardí cultivado, educado a la manera occidental, políglota, pero conocedor desde la infancia del patrimonio tradicional sefardí. Benoliel envió a Menéndez Pidal más de ciento cincuenta romances y canciones que conocía por tradición propia o de las personas de su entorno cercano; él mismo publicó un largo artículo en cuatro entregas (Benoliel 1926-1952) sobre la hakitía o judeoespañol de Marruecos, en una de cuyas partes publica varios romances y canciones.

Sin embargo, la aportación de Menéndez Pidal al romancero sefardí no se limitó a impulsar la recolección de textos en encuestas de campo y a elaborar un primer catálogo de la tradición sefardita para facilitar la recolección (1906 y reeds.); más importante todavía fue que tuvo en cuenta la tradición sefardí en todos sus estudios sobre el romancero, como en su fundamental libro de 1953. Un criterio que han continuado los discípulos y seguidores de Menéndez Pidal (véanse, por ejemplo, los artículos recopilados en Catalán 1969, 1970 y $1997-$ 
1998)... y también sus detractores, de forma que hoy en día es inconcebible abordar un estudio sobre el romancero hispánico sin tomar en consideración la rama sefardí.

Paralelamente, el romancero sefardí fue recibiendo la atención de estudiosos de la literatura, desde los más diversos puntos de vista. Especial relevancia tuvieron en sus respectivos momentos los trabajos de William Entwistle (por ejemplo, su trabajo sobre La dama de Aragón de 1938, o el de 1951 sobre el Conde Olinos), que encuadraron el romancero hispánico en general (y el sefardí en particular) en el marco del género internacional de la balada, descubriendo interesantes paralelos e influencias de baladas no hispánicas (una línea de investigación que fue luego continuada por Armistead y Silverman en todos sus trabajos); el análisis semiótico del romancero sefardí abordado desde distintas perspectivas por estudiosos como Giuseppe di Stefano (por ejemplo, 1967) o Diego Catalán y sus colaboradores (en el catálogo de 1982-1984). O el análisis de la poética del romancero (tratado como cualquier otro género literario) que abordó Paul Bénichou (1968). En este último caso volvemos a encontrar — aunque con formación y metodología más rigurosa y moderna que en los casos de Danon, Galante o Benoliel - el ejemplo de un sefardí que aborda con orientación académica la tradición oral que él conoce de primera mano: los estudios sobre la poética del romancero de Bénichou toman como base los romances de Tetuán que el propio estudioso pudo recolectar entre sus familiares residentes en Orán y en Argentina (que publicó en 1944 y 1968a).

\section{El descubrimiento de las ediciones aljamiadas}

Hasta ahora hemos hablado de ediciones y estudios del romancero sefardí que toman como base la tradición estrictamente oral, bien a través de la recolección en encuestas de campo, 
bien (en el caso de los romances sefardíes publicados por sefardíes) por la publicación, difusión y análisis de muestras de la propia tradición familiar de los estudiosos.

Pero los sefarditas también imprimieron literatura para su propio uso, principalmente en ediciones aljamiadas. ${ }^{5}$ Entre los textos que imprimieron había también libritos de cordel aljamiados con romances.

Los romances impresos en aljamía no recibieron atención de los estudiosos hasta muy tarde, por razones explicables: los romanistas e hispanistas que fueron los primeros en ocuparse del romancero sefardí no tenían acceso a esos textos por desconocimiento del alfabeto hebreo; y los hebraístas tampoco les prestaron atención por no ser literatura hebrea. Sólo algunos de los primeros encuestadores (como el mismo Manuel Manrique de Lara o Max Leopold Wagner) manejaron textos aljamiados manuscritos o impresos, y los transcribieron en sus encuestas (no sabemos si los leyeron ellos personalmente o se los hicieron leer).

La situación cambió a partir de la década de 1970, principalmente por la labor de Samuel G. Armistead y Joseph H. Silverman, quienes empezaron a editar y estudiar los romances incluidos en libritos aljamiados de cordel impresos en diversas ciudades de Oriente (por ejemplo, en su libro con Hassán de 1981); especial importancia tiene su edición y estudio de los romances publicados por un impresor de Salónica (1971), Ya'acob Abraham Yoná, que entre finales del siglo XIX y 1920 publicó no menos de ocho folletitos con romances, además de otros con coplas compuestas por él mismo, refranes, textos satíricos, etc. Yoná representa, a principios del siglo xx, la antítesis de los publicistas sefardíes educados a la occidental que por esa misma época daban a conocer el romancero sefardí en revistas académicas francesas, o de los aburguesados sefarditas corres-

\footnotetext{
${ }^{5}$ Una síntesis de las prácticas editoriales y lectoras sefardíes puede verse en Díaz-Mas 2004.
} 
ponsales de Pulido: se trata de un autor e impresor popular completamente inmerso en la vida tradicional, que componía, imprimía, vendía y hasta recitaba su producción, y que se dirige también a un público popular, entre el que todavía permanecían vivos la educación y los modos de vida tradicionales y la literatura a ellos aparejada.

\section{Romancero sefardí y música sefardí: las colecciones de himnarios litúrgicos}

No podemos olvidar que los romances son, sobre todo, poemas narrativos cantables, que se entonaban más que se recitaban, se transmitían por el canto y se aprendían de oírlos cantar.

Esos romances cantados tuvieron un papel importante en la vida tradicional sefardí; aparte de su uso puramente lúdico y de entretenimiento, se utilizaron para acompañar muchas circunstancias vitales, desde las más triviales y cotidianas (como acunar a los niños o marcar el ritmo de tareas artesanales o domésticas) hasta los más festivos (algunos romances se usaron como canto ritual en las celebraciones del ciclo vital, como la boda o la circuncisión) o solemnes (tal es el caso de los romances que se cantaban para endechar, o en determinadas ocasiones litúrgicas).

Algunos romances y canciones llegaron a ser tan conocidos que bastaba mencionar su incipit o una formulación significativa para que todo el mundo pudiera identificarlos. Sus melodías debieron ser tan conocidas como sus letras, así se explica que encontremos incipits, versos de romances, canciones en colecciones de himnos y cantos litúrgicos en hebreo (piyutim) sefardíes, para indicar la música con la que se entonaba el canto sinagogal en cuestión. Por lo general, se trata de manuscritos usados por cantores sinagogales (hazanim) como recordatorio o apoyo de su labor; a veces los manuscritos pueden haber pasa- 
do de mano en mano, de un cantor a otro, a lo largo de varias generaciones.

Los primeros en prestar atención a la presencia de versos de romances hispánicos en himnarios hebreos de los sefardíes de Oriente fue Hanoch Avenary (1960, 1971); después, Armistead y Silverman exploraron la presencia de romances en colecciones de piyutim (1973, 1981). Y actualmente el musicólogo Edwin Seroussi, de la Universidad Hebrea de Jerusalén, prepara un repertorio completo de los incipits de romances y canciones hispánicos encontrados en numerosos manuscritos (la mayoría, aljamiados) de los siglos XV al XIX (véanse sus artículos preliminares de 1993 y en prensa); entre ellos hay versos de romances que nos son conocidos exclusivamente por la tradición oral moderna, al no haberse conservado ninguna versión antigua, con lo cual es la breve cita en un himnario sefardí (por ejemplo, del siglo XVI o XVII) la documentación más antigua de ese tema romancístico. En otras ocasiones se comprueba que el canto sinagogal hebreo está construido como un contrafactum del romance hispánico, del cual imita no sólo patrones rítmicos, sino la rima, e incluso las formulaciones hebreas buscan la homofonía con las formulaciones castellanas del romance.

En todo caso, la presencia de versos de romances en colecciones de piyutim hebreos nos indican la profunda imbricación del romancero en la cultura sefardí: no sólo algunos cantos litúrgicos se cantaban con música de romances conocidos, sino que los mismos piyutim hebreos se construyeron a veces sobre el patrón de romances.

\section{Los cuadernos manuscritos o el romancero} como patrimonio personal y familiar

Como ya hemos señalado, la mayor parte de estos himnarios hebreos son, precisamente, manuscritos compilados personal- 
mente por cantores sinagogales como instrumento de apoyo de su actividad profesional. En alguno de estos manuscritos de hazanim encontramos, además de los cantos litúrgicos esperables (en los que pueden señalarse o no versos de romances como indicación de la melodía) apartados en los que se han copiado —al margen de la función utilitaria y por puro gusto- romances y otros cantos tradicionales: tal es el caso del manuscrito de Yacov Hazán, compilado en la isla de Rodas entre finales del siglo XVIII y principios del xx, que contiene sobre todo cantos litúrgicos, pero en cuyas últimas hojas hay canciones y romances profanos en judeoárabe, turco y judeoespañol (Armistead y Silverman 1962, 11-79).

Sin embargo, la copia de manuscritos de uso personal (en los que muchas veces se incluyen romances) no fue práctica exclusiva de los cantores sinagogales. Y así, tenemos documentada la existencia de manuscritos personales con romances y canciones entre la primera mitad del siglo XVIII y los años ochenta del siglo xx; su importancia es, además, especial para conocer la literatura de los sefardíes norteafricanos, ya que en Marruecos no existió imprenta judía — como sí la hubo en las tierras del imperio otomano, ya desde el siglo xvI-, de modo que los únicos textos judeoespañoles de Marruecos que nos han llegado son precisamente los manuscritos.

La tipología de los manuscritos romancísticos difiere de unos lugares a otros y de unas épocas a otras. En los siglos XVIII y XIX son fundamentalmente compilaciones hechas por hombres, en las que dominan los textos con una funcionalidad en la vida religiosa (piyutim en hebreo y en judeoespañol, coplas paralitúrgicas en judeoespañol, romances de función ritual en las festividades religiosas o en las ceremonias del ciclo vital), aunque a veces puedan haberse copiado textos profanos por el mero gusto de tenerlos, conservarlos y recordarlos.

Sin embargo, a partir de las primeras décadas del siglo $\mathrm{xx}, \mathrm{y}$ hasta casi los umbrales del XXI, se da un fenómeno de especial 
interés: los manuscritos de uso personal compilados por mujeres, que - aunque puedan contener coplas paralitúrgicas o traducciones de piyutim en ladino - recogen sobre todo romances, canciones y otros cantos tradicionales o no; en muchos se incluyen, junto a casticísimas versiones de romances viejos, letras de tangos, de cuplés o de copla folklórica española. En otras palabras: lo que cantaban las mujeres sefardíes del siglo xx, que incorporaban a su repertorio de cantares (así se denominaba en Marruecos todo poema cantado, tradicional o no), tanto los viejos romances aprendidos de sus madres o abuelas como las nuevas letras de moda que llegaban a través de espectáculos teatrales, de la radio o de las primeras grabaciones en disco.

Desde la década de 1980 se han ido dando a conocer, editando y estudiando varios de estos manuscritos sefardíes de mujeres, sobre todo de Marruecos: así, en 1988, Oro Anahory editó un par de estos manuscritos compilados por sendas mujeres sefardíes de Tetuán (Luna Bennaim y Esther Benchimol) que habían ido a asentarse en Canadá con sus familias como consecuencia de uno de tantos fenómenos migratorios de la diáspora secundaria. Luna Bennaim, sin embargo, no copió un solo manuscrito: yo misma he dado a conocer (1994) y me propongo editar otro más extenso que el publicado por Anahory, compilado por la misma señora. Por otra parte, la musicóloga israelí Susana Weich-Shahak (véase 1995 y también Seroussi 2003) ha recibido de sus informantes marroquíes residentes en Israel varios manuscritos de este tipo, algunos de ellos con interesantísimas versiones. Uno de los manuscritos más antiguos es, sin embargo, el copiado en 1934 por la tetuaní residente en Tánger, Halia Isaac Cohen, cuyos romances ha editado y estudiado Hilary Pomeroy (2005). El más reciente que conozco es el copiado por una sefardí de Alcazarquivir, Clara Benoudis, en París a principios de la década de los años ochenta del siglo xx. ${ }^{6}$

\footnotetext{
${ }^{6}$ Sobre el cuaderno de cantares de Clara Benoudis se celebró en la Universidad de Lisboa en diciembre de 2004 el congreso "Romances de Alcácer Quibir",
} 
Aunque los casos que he mencionado hasta ahora son de manuscritos marroquíes, también se da el mismo fenómeno entre las sefardíes de Oriente: ya en 1911, Manuel Manrique de Lara tuvo en sus manos varios manuscritos aljamiados con romances, uno de ellos copiado por Elisa Bottón, una joven salonicense de sólo 14 años. Rivka Havassy prepara actualmente su tesis doctoral en la Universidad Hebrea de Jerusalén sobre sendos manuscritos copiados por Emily Sene, sefardí de Edirne cuya familia se trasladó a Estambul y que en 1925 emigró a Cuba y posteriormente (en 1928) a Estados Unidos, donde vivió en Nueva York y Los Ángeles; y por Bouena Sarfaty-Garfinkle, de Salónica, que emigró a Palestina tras la segunda guerra mundial y luego (ca. 1947-1948) a Canadá, donde copió su manuscrito.

Naturalmente, también existen manuscritos compilados por hombres, pero lo que interesa resaltar aquí es la proliferación de compilaciones romancísticas hechas por mujeres en unos años que van, aproximadamente, de 1920 a 1980.

Casi todos esos manuscritos comparten unas mismas características: están hechos con cuadernos escolares y copiados en caracteres latinos (normalmente, con un tipo de letra que muestra que sus autoras se habían educado en escuelas occidentales); se elaboraron a lo largo de una serie de años (a veces décadas) por mujeres a las que les gustaba especialmente cantar los viejos romances y canciones que habían aprendido de sus madres; en ocasiones intervinieron en el proceso de elaboración varios miembros de una misma familia (caso de los dos de Luna Bennaim); se han encontrado en lugares de la diáspora secundaria (España, Israel, Canadá o Estados Unidos y países de Hispanoamérica), bien porque se copiaron en los países de emigración, bien porque se compilaron en una de las comunidades tradicionales y las familias los llevaron consigo a

cuyas actas están en proceso de edición; podrá verse allí una contribución mía sobre los cuadernos de mujeres. 
la emigración; en muchas ocasiones hay una intención implícita o expresa de elaborar el manuscrito como legado a los sucesores, o en memoria de los antepasados: así, en uno de los manuscritos manejados por Susana Weich-Shahak, el de Azibuena Barujel, fue copiado en realidad por su hija Flora, quien puso como frontispicio "Canciones del Norte de Marruecos. Romances de Tetuán. A la Santa Memoria de la Señora Azibuena Barujel como Recuerdo para sus hijas Meriam, Esther, Flora Barujel y Rachel Barujel, Tetuán, Marruecos", bien expresivo de su voluntad de preservar la memoria de la madre a través de los cantares y de convertir ese patrimonio en un legado familiar.

Cabe preguntarse el por qué de esa práctica de compilación de romances y canciones en cuadernos de mujeres. Susana Weich ha recogido entre sus informantes el testimonio de que, en Marruecos, las mujeres competían entre ellas por elaborar el manuscrito más completo y con más textos, pero lo cierto es que la mayoría de las autoras de los cuadernos que han llegado hasta nosotros no se conocían entre sí, e incluso procedían de lugares tan dispares como Edirne y Alcazaquivir, o copiaron los textos en Estados Unidos, en París o en Canadá; así que no todos los casos pueden explicarse por un afán de emulación entre personas de un círculo relativamente restringido, sino han de deberse, por decirlo así, a una iniciativa poligenética. ¿A qué se debió ese impulso tan extendido, que llevó a las mujeres sefardíes, desde la tercera década del siglo $\mathrm{xx}$, a poner por escrito, en sencillos cuadernos escolares, los cantares que se sabían?

Creo que es debido a un cambio en la situación social y cultural. Las mujeres sefardíes van teniendo acceso a la escolarización y a la cultura de los libros desde finales del siglo XIX (es decir, con varias décadas de retraso con respecto a los varones). Esas mujeres que acceden a la educación y a la cultura libresca conservan todavía los saberes tradicionales recibidos 
por transmisión oral de sus madres o abuelas; por otra parte, son conscientes de que la educación que reciban sus hijos e hijas será ya - más todavía que la suya propia - una formación académica, de cuño libresco, en la que la transmisión oral de saberes (incluida la literatura oral) tendrá un papel secundario y marginal. Además, por la misma época, el aumento de la emigración de grupos familiares a otros países produce el desarraigo con respecto al ambiente tradicional y el abandono de las costumbres ancestrales (y el olvido de la literatura a ellas aparejada).

En esa situación, algunas mujeres sefardíes del siglo xx dan el paso de convertirse no ya en depositarias de la tradición, sino en notarias de la tradición, dejando constancia por escrito de la literatura de tradición oral; en parte, para preservarla para sí mismas, pero también para transmitir ese legado a sus descendientes.

En el afán de estas mujeres por recopilar cuadernos de cantares se traslucen, pues, una conciencia de la propia identidad cultural y una postura activa de conservación de lo que se siente como parte de un patrimonio cultural en vías de extinción.

\section{REFERENCIAS}

Anahory [Librowicz], Oro, 1988. Cancionero Séphardi du Québec, vol. I, Montréal, Collège du Vieux Montréal.

Armistead, Samuel G., 1978. El Romancero judeo-español en el Archivo Menéndez Pidal (Catálogo-Índice de romances y canciones), 3 vols., Madrid, Cátedra Seminario Menéndez Pidal.

- y Joseph H. Silverman, 1962. Diez romances hispánicos en un manuscrito sefardí de la Isla de Rodas, Pisa, Universidad.

—, 1971. The Judeo-Spanish Ballad Chapbooks of Yacob Abraham

Yoná, Berkeley-Los Ángeles-Londres, University of California Press.

—, 1973. "El cancionero judeo-español de Marruecos en el siglo 
XVIII (Incipits de los Ben-Çur)", Nueva Revista de Filología Hispánica 22, 280-290.

Armistead, Samuel G. y Joseph H. Silverman, 1979. Tres calas en el Romancero sefardí (Rodas, Jerusalén y Estados Unidos), transcripciones musicales y estudio de Israel J. Katz, Madrid, Castalia.

—, 1981. "El antiguo romancero sefardí: citas de romances en himnarios hebreos (siglos XVI-XIX)", Nueva Revista de Filología Hispánica 30, 453-512.

—, 1982. En torno al romancero sefardí (Hispanismo y balcanismo de la tradición judeoespañola), Madrid, Seminario Menéndez Pidal.

- y Iacob M. Hassán, 1981. Seis romancerillos de cordel sefardies, Madrid, Castalia.

Avenary, Hanoch, 1960. "Études sur le cancionero judéo-espagnol (xvie et xvire siècles)", Sefarad 20, 377-394.

—, 1971. "Cantos españoles antiguos mencionados en la literatura hebrea", Anuario Musical 25, 67-79.

BÉnichou, Paul, 1944. "Romances judeo-españoles de Marruecos", Revista de Filología Hispánica 6, 36-76.

—, 1968a, Romancero judeo-español de Marruecos, Madrid, Castalia.

—, 1968b, Creación poética en el romancero tradicional, Madrid, Gredos.

Benoliel, José, 1926. "Dialecto judeo-hispano-marroquí o Hakitía", Boletín de la Real Academia Española, 13, 209-233, 342363, 507-538; 14 (1927), 137-168, 196-234, 357-373, 566-580; 15 (1928), 47-61, 188-223; 22 (1952), 255-289.

Catalán, Diego, et al., 1982-84. El Romancero pan-hispánico. Catálogo general descriptivo, 3 vols., Madrid, Seminario Menéndez Pidal.

—, 1969. Siete siglos de Romancero (Historia y poesía), Madrid, Gredos.

—, 1970. Por campos del Romancero. Estudios sobre la tradición oral moderna, Madrid, Gredos.

—, 1997. Arte poética del romancero oral. Parte $1^{a}$. Los textos abiertos de creación colectiva, Madrid, Siglo XXI.

—, 1998. Arte poética del romancero oral. Parte $2^{a}$ Memoria, invención, artificio, Madrid, Siglo XXI. 
Catalán, Diego, 2001. El archivo del Romancero. Patrimonio de la Humanidad (Historia documentada de un siglo de Historia), vol. I, Madrid, Fundación Menéndez Pidal-Universidad Complutense.

Cohen, Judith, 1988. Judeo-Spanish Folk Songs in the Sephardic Communities of Montreal and Toronto: Survival, Function and Change, Montreal, University of Montreal.

Crews, Cynthia M. 1935, Recherches sur le Judéo-Espagnol dans les Pays Balkaniques, Paris, Droz.

—, 1979. "Textos judeo-españoles de Salónica y Sarajevo con comentarios lingüísticos y glosario", Estudios sefardíes 2, 91-258.

Danon, Abraham, 1896. "Recueil de romances judéo-espagnoles chantées en Turquie", Revue des Études Juives 32, 1896, 102123, 263-275; 33, 122-139, 255-268.

Díaz-MAs, Paloma, 1992. Los sefardies: Historia, lengua y cultura, Barcelona, Riopiedras [traducción al inglés: Sephardim. The Jews from Spain, por George K. Zucker, Chicago-Londres, The University of Chicago Press, 1986].

—, 1994. "Los romances tetuaníes del manuscrito de Luna Bennaim", en De balada y lírica, 2. 3er Coloquio Internacional del Romancero, Madrid, Fundación Menéndez Pidal-Universidad Complutense de Madrid, pp. 255-262.

—, 2001. "Corresponsales de Ángel Pulido e informantes de Menéndez Pidal: dos mundos sefardíes", en 'Los trigos ya van en flores' Studia in Honorem Michelle Débax, Toulouse-le Mirail, Universidad, pp. 103-116.

—, 2004. "El libro y la lectura entre los sefardíes de Oriente", en $L a$ memoria de los libros. Estudios sobre la historia del escrito y de la lectura en Europa y América, vol. II, Madrid, Instituto de Historia del Libro y de la Lectura, Madrid, pp. 85-100.

Entwistle, William, 1938. "La dama de Aragón", Hispanic Review 6, 185-192.

—, 1951. "El Conde Olinos", Revista de Filología Española 35, 237-248.

Galante, Abraham, 1903. "Quatorze romances judéo-espagnols", Revue Hispanique 10, 544-606.

MenÉndez Pidal, Ramón, 1939. "Catálogo del romancero judío-español”, Cultura española 4, 1906, 1.045-1.077 y 5, 1907, 161-199; reed. en El Romancero: teorías e investigaciones, Madrid, 1927, 
pp. 101-183 y en Los romances de América y otros estudios, Madrid, Espasa Calpe, pp. 114-179.

Menéndez Pidal, 2005 [1953]. Romancero hispánico (Hispanoportugués, americano y sefardí). Teoría e historia, 2 vols., Madrid, Espasa Calpe.

Pomeroy, Hilary, An Edition and Study of the Secular Ballads in the Sephardic Ballad Notebook of Halia Isaac Cohen, Newark Delaware, Juan de la Cuesta.

Pulido, Ángel, 1904. Los israelitas españoles y el idioma castellano, Madrid, Sucesores de Rivadeneyra; reed. facsímil, Barcelona, Ríopiedras, 1992.

—, 1905. Españoles sin patria y la raza sefardí, Madrid, E. Teodoro; reed. facsímil, Granada, Universidad, 1993.

Romero, Elena, 1992. La creación literaria en lengua sefardí, Madrid, Mapfre.

SERoussi, Edwin, 1993. "La música sefardí en el imperio otomano: nuevas fuentes literarias", en Actes del Simposi Internacional sobre Cultura Sefardita, Barcelona, PPU, pp. 279-294.

—, 2003. "Archivists of Memory: Written Folksong Collections of Twentieth-Century Sephardi Women", en Music and Gender. Perspectives from the Mediterranean, Chicago-Londres, The University of Chicago Press, pp. 195-214.

—, 2003. "Canciones en romance como modelos de poesía hebrea del siglo xv", Sefarad (en prensa).

Stefano, Giuseppe Di, 1967. Sincronia e diacronia nel Romanzero (Un esempio di lectura), Pisa, Universidad.

W AGNER, Max Leopold, 1914. Beiträge zur kenntnis des Judenspanischen von Konstantinopel, Viena, Alfred Hölder.

—, 1930. Caracteres generales del judeoespañol de Oriente, Madrid, Anejos de la Revista de Filología Española.

Weich-ShahaK, Susana, 1995. "El cancionero sefardí de Bulgaria. Kantikas viejas: Avance de un catálogo y edición crítica", Anuario Musical 50, 61-74.

WiENER, Leo, 1903-1904. "Songs of the Spanish Jews in the Balkan Peninsula”, Modern Philology I, 205-216, 259-274. 